\title{
Exergoeconomic optimization of coaxial tube evaporators for cooling of high pressure gaseous hydrogen during vehicle fuelling
}

\author{
Jensen, Jonas Kjær; Rothuizen, Erasmus Damgaard; Markussen, Wiebke Brix
}

Published in:

Energy Conversion and Management

Link to article, DOI:

10.1016/j.enconman.2014.02.023

Publication date:

2014

Link back to DTU Orbit

Citation (APA):

Jensen, J. K., Rothuizen, E. D., \& Markussen, W. B. (2014). Exergoeconomic optimization of coaxial tube evaporators for cooling of high pressure gaseous hydrogen during vehicle fuelling. Energy Conversion and Management, 85, 740-749. https://doi.org/10.1016/j.enconman.2014.02.023

\section{General rights}

Copyright and moral rights for the publications made accessible in the public portal are retained by the authors and/or other copyright owners and it is a condition of accessing publications that users recognise and abide by the legal requirements associated with these rights.

- Users may download and print one copy of any publication from the public portal for the purpose of private study or research.

- You may not further distribute the material or use it for any profit-making activity or commercial gain

- You may freely distribute the URL identifying the publication in the public portal 


\title{
Exergoeconomic optimization of coaxial tube evaporators for cooling of high pressure gaseous hydrogen during vehicle fuelling
}

\author{
Jonas K. Jensen $^{\mathrm{a}, *}$, Erasmus D. Rothuizen ${ }^{\mathrm{a}}$, Wiebke B. Markussen ${ }^{\mathrm{a}}$ \\ ${ }^{a}$ Technical University of Denmark, Department of Mechanical Engineering, Nils Koppels Alle, Building 403, DK - 2800, Kgs. Lyngby, Denmark
}

\begin{abstract}
Gaseous hydrogen as an automotive fuel is reaching the point of commercial introduction. Development of hydrogen fuelling stations considering an acceptable fuelling time by cooling the hydrogen to $-40{ }^{\circ} \mathrm{C}$ has started. This paper presents a design study of coaxial tube ammonia evaporators for three different concepts of hydrogen cooling, one onestage and two two-stage processes. An exergoeconomic optimization is imposed to all three concepts to minimize the total cost. A numerical heat transfer model is developed in Engineer Equation Solver, using heat transfer and pressure drop correlations from the open literature. With this model the optimal choice of tube sizes and circuit numbers are found for all three concepts. The results show that cooling with a two-stage evaporator after the pressure reduction valve yields the lowest total cost, $45 \%$ lower than the highest, which is with a one-stage evaporator. The main contribution to the total cost was the cost associated with exergy destruction, the capital investment cost contributed with 5-14\%. The main contribution to the exergy destruction was found to be thermally driven. The pressure driven exergy destruction accounted for 3-9\%.
\end{abstract}

Keywords: Exergoeconomic optimization, Evaporator design, Heat transfer modelling, Hydrogen fuelling, Hydrogen fast filling

\section{Introduction}

Fossil fuel depletion and carbon-dioxide emission are two of the main factors that must be considered when assessing energy for private transport. A transition from fossil fuels to renewable and zero emission energy is a requirement for the development of a sustainable transport sector. Introducing hydrogen as a fuel for private transportation is one measure for addressing these issues. In recent years research and development on gaseous hydrogen fuel cell vehicles has matured the technology to the point of commercial introduction. This coming fleet of hydrogen vehicles will require a hydrogen infrastructure that includes hydrogen fuelling stations. The development of hydrogen fuelling stations has two often opposing objectives: low energy consumption and high customer acceptance, the former to comply with the sustainability aspect, the latter to compete with conventional petrol or diesel fuelling.

Hydrogen vehicles reach a tank pressure of $70 \mathrm{MPa}$ after fuelling from a hydrogen bank maintained at $90 \mathrm{MPa}[1]$ or through a cascade fuelling system[2]. To regulate the fuelling duration an actuated pressure reduction valve is placed in the hydrogen dispenser. This valve maintains a linear pressure increase in the vehicle's hydrogen tank. To compete with conventional fuelling the duration must be as short as possible. Conversely, if the fuelling duration is too short it will lead to overheating of the tank. The heat is generated by three phenomena[3][4]: the heat of compression, the conversion of kinetic to internal energy and the negative Joule-Thomson coefficient of hydrogen. The negative Joule-Thomson coefficient causes a temperature increase of hydrogen when it is subjected to a forced adiabatic expansion.

The fuelling duration can be reduced without overheating the hydrogen tank by cooling the hydrogen before it enters the vehicle[5]. The relation between fuelling duration and cooling temperature is given by SAE-tir-J2600[6]

\footnotetext{
* Corresponding author

Email addresses: jkjje@mek.dtu.dk (Jonas K. Jensen), edro@mek.dtu.dk (Erasmus D. Rothuizen), wb@mek.dtu.dk (Wiebke B. Markussen)
} 


\begin{tabular}{|c|c|}
\hline \multicolumn{2}{|l|}{ Nomenclature } \\
\hline$C \operatorname{cost}(\$)$ & $\Delta$ difference \\
\hline$D$ diameter $(\mathrm{m})$ & $\epsilon$ absolute roughness $(\mathrm{m})$ \\
\hline$E$ exergy $(\mathrm{kW})$ & $\rho$ density $\left(\mathrm{m}^{3} / \mathrm{kg}\right)$ \\
\hline$I$ life time (years) & \\
\hline$L$ length (m) & Superscripts \\
\hline & CI capital investment \\
\hline $\begin{array}{l}\text { LS nign-stage load-snare (-) } \\
N \text { number of tube in twhe circuits (-) }\end{array}$ & $M$ mechanical \\
\hline$N$ number of tube in tube circuits (-) & OP operation \\
\hline$T$ temperature $(\mathrm{C})$ & PH physical \\
\hline UA over all heat transfer coefficient $\left(\mathrm{kW} / \mathrm{m}^{2}-\mathrm{K}\right)$ & TI total investment \\
\hline$V$ volume $\left(\mathrm{m}^{3}\right)$ & $T$ thermal \\
\hline$\dot{Q}$ heat load $(\mathrm{kW})$ & \\
\hline$\dot{m}$ mass flow rate $(\mathrm{kg} / \mathrm{s})$ & Subscripts \\
\hline$c$ specific cost $(\$ / \mathrm{kg})$ & 0 dead state \\
\hline$e$ specific exergy $(\mathrm{kW} / \mathrm{kg})$ & $\mathrm{C} 1$ concept 1 \\
\hline$f$ exergoeconomic factor (-) & $\mathrm{C} 2$ concept 2 \\
\hline$h$ specific enthalpy $(\mathrm{kj} / \mathrm{kg})$ & C3 concept 3 \\
\hline$k$ conductivity $(\mathrm{kW} / \mathrm{m}-\mathrm{K})$ & $c$ circuit \\
\hline$n$ number of (-) & $f$ fuel \\
\hline$p$ pressure (atm) & hyd hydrogen \\
\hline$r$ interest rate (-) & $H$ high-stage \\
\hline$r$ real roughness of pipe (-) & in flow into control volume \\
\hline$s$ specific entropy $(\mathrm{kj} / \mathrm{kg}-\mathrm{K})$ & $i$ inner \\
\hline$t$ pipe wall thickness $(\mathrm{m})$ & $j \mathrm{j}$ 'th stream \\
\hline$x$ vapour mass fraction (vapour quality) (-) & $L$ low-stage \\
\hline Abbreviations & mat material \\
\hline COP coefficient of performance & $M$ mechanical \\
\hline CV control volume & $m$ minimum \\
\hline EES engineering equation solver & oh operating hours $(\mathrm{h})$ \\
\hline HPS hydrogen pipe size & opt optimal \\
\hline NPS nominal nine size & out flow out of control volume \\
\hline $\begin{array}{l}\text { NPS nominal pipe size } \\
\text { RPS refrigerant nine size }\end{array}$ & $o$ outer \\
\hline RPS refrigerant pipe size & ref refrigerant \\
\hline Greek letters & $\mathrm{RV}$ reduction valve \\
\hline $\bar{\alpha}$ average heat transfer coefficient $\left(\mathrm{kW} / \mathrm{m}^{2}-\mathrm{K}\right)$ & tot total \\
\hline
\end{tabular}

and SAE-tir-J2601[7]. For hydrogen vehicles with tank capacities of $1-7 \mathrm{~kg}$ a cooling temperature of $-40{ }^{\circ} \mathrm{C}$ is advised. To reduce the energy consumption required to attain this, the refrigeration system should be designed to minimize the exergy destruction within it. A reduction of exergy destruction in a vapour compression refrigeration system is best achieved by improving the evaporator, as the endogenous avoidable exergy destruction is highest in this component[8].

The recent research and development in hydrogen fuelling has been focused in part on the physical phenomenon under fast filling of hydrogen tanks[3, 4, 9, 5] and in part on the overall energy efficiency of hydrogen fuelling stations[1,2]. Although SAE-tir-J2600[6] and SAE-tir-J2601[7] state that cooling is required little research has been published on how these refrigeration systems should be designed. Rothuizen et al.[10] investigated the use of an indirect refrigeration system with an acetate brine to cool hydrogen under fuelling. This has the advantage of storing cooling capacity in the brine but has the disadvantage of a large heat ingress to the tank and distribution system caused by the continuous circulation of the brine to prevent icy clods from plugging the system.

This study will investigate the use of a direct refrigeration system in which the hydrogen is cooled directly by 


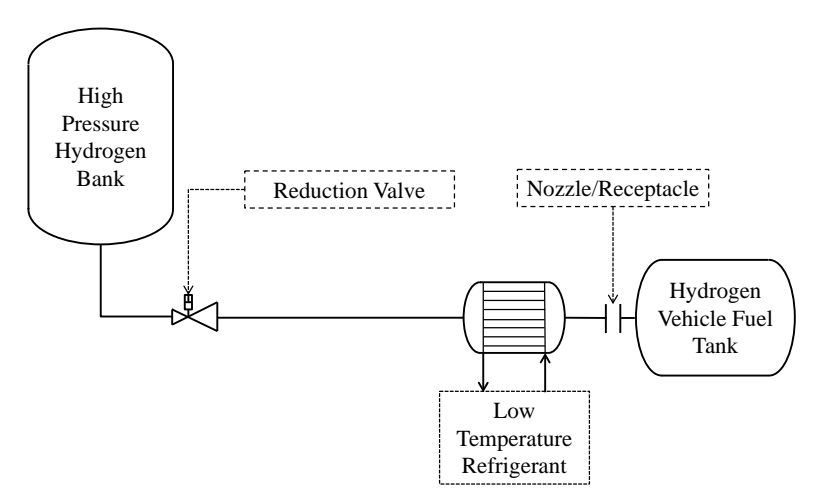

(a)

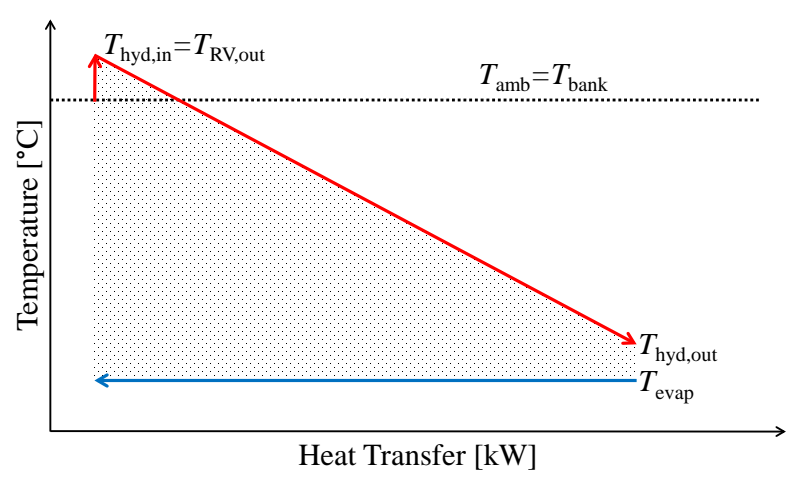

(b)

Figure 1: (a) PID of hydrogen cooling Concept 1. (b) $\dot{Q}-T$ diagram of hydrogen cooling Concept 1

an evaporative stream of refrigerant. A refrigeration system such as this can be run only when the station is fuelling and thus can reduce the energy consumption compared to an indirect system. Three concepts for applying direct evaporation refrigeration systems has been identified. The choice of evaporator design is highly influenced by the pressure of up to $90 \mathrm{MPa}$ in the hydrogen supply system. This eliminates the application of typical heat exchanger designs such as brazed plate or plate and shell. It is a general assumption that all hydrogen conduits must be composed of high pressure pipes. The coaxial tube evaporator can be designed with these restrictions and is therefore chosen. Due to the Joule-Thomson effect the evaporator must be placed as close as possible to the exit of the station[7]. The evaporator must therefore be built into the hydrogen dispenser, which makes the size a constrained parameter.

The size of the evaporator is governed by the choice of design variables such as pipe dimensions and the number of parallel circuits. Size is typically minimized by increasing flow velocity but this will typically cause increased pressure loss. To find the best trade-off design between these opposing effects an exergoeconomic optimization is applied. Exergoeconomic optimization is a generalized method for minimization of the total cost of a component. It is described in literature by Tsatsaronis[11], Kotas[12] and Bejan et al.[13]. The exergoeconomic optimization method has been applied to determine optimal design variables for heat exchangers in[14, 15, 16]. The total cost of a component is comprised by the capital investment and maintenance cost, the so called non-exergetic cost, and the cost of thermodynamic irreversibilities i.e. exergy destruction. Thereby the exergoeconomic optimization is a multi-objective minimization of the non-exergetic and exergetic cost.

This study will seek to determine exergoeconomic optimum designs for three concepts of direct evaporation hydrogen cooling heat exchangers. The objective of the optimization is to minimize the total cost of an evaporator that meets the requirements of SAE-tir-J2601[7] and SAE-tir-J2600[6] and satisfies the spatial constraints. The optimization is subjected to three decision variables: the hydrogen pipe size, the refrigerant pipe size and the number of parallel circuits. Ammonia was chosen as the refrigerant as it has no ozone depletion potential and a global warming potential that is $<1[17]$. Ammonia also has good thermophysical properties in the required operating range.

\subsection{System Description}

\subsubsection{Load and temperature levels}

For a fuelling that complies with SAE-tir-J2600[6] and SAE-tir-J2601[7] the peak cooling load occurs at an ambient temperature of $30^{\circ} \mathrm{C}$ and an initial tank pressure of $2 \mathrm{MPa}$ [1]. Under these conditions the fuelling duration is $150 \mathrm{~s}$ [7]. The peak cooling load occurs approximately half way through the fuelling and is $72 \mathrm{~kW}$ [1]. At the peak load the hydrogen mass flow rate is $0.05 \mathrm{~kg} / \mathrm{s}$ and the hydrogen tank pressure of the vehicle is $36.5 \mathrm{MPa}[1]$. The hydrogen bank temperature and pressure are assumed to remain constant at $30{ }^{\circ} \mathrm{C}$ and $90 \mathrm{MPa}$ respectively. These values were used as the dimensioning conditions for all three concepts.

\subsubsection{Cooling Concept 1}

Concept 1 utilizes one evaporative cold stream. The principle layout can be seen in Fig. 1a. As may be seen, one hydrogen cooling heat exchanger is placed between the reduction valve and the nozzle. This heat exchanger must cool 


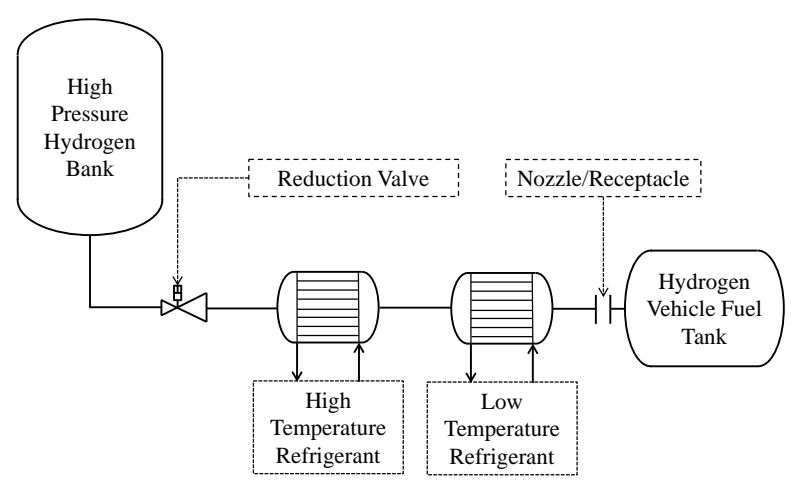

(a)

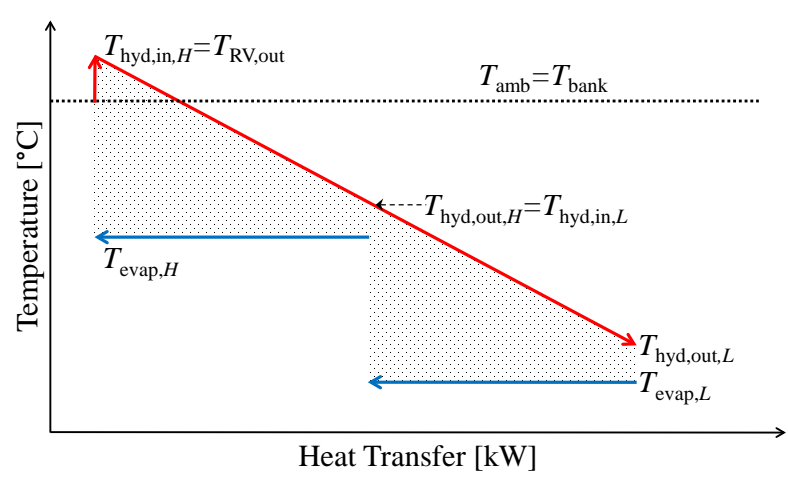

(b)

Figure 2: (a) PID of hydrogen cooling Concept 2. (b) $\dot{Q}-T$ diagram of hydrogen cooling Concept 2

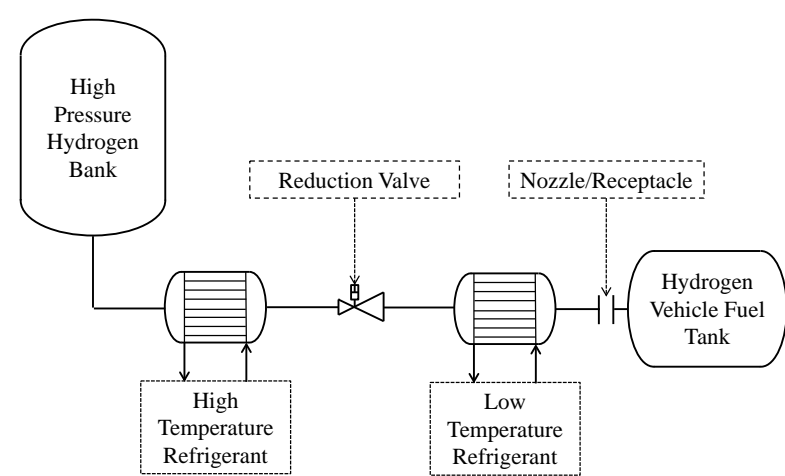

(a)

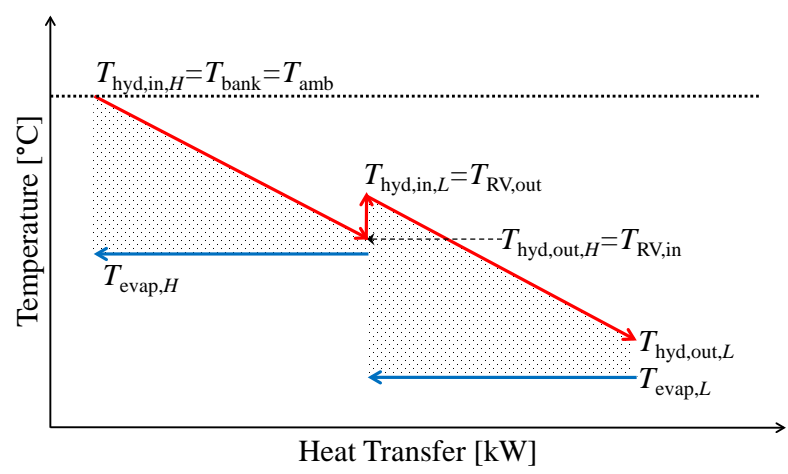

(b)

Figure 3: (a) PID of hydrogen cooling Concept 3. (b) $\dot{Q}-T$ diagram of hydrogen cooling Concept 3

the fuelling flow of hydrogen to the target temperature of $-40{ }^{\circ} \mathrm{C}$ and hence $T_{\text {evap }}<-40{ }^{\circ} \mathrm{C}$. Fig. $1 \mathrm{~b}$ shows a $\dot{Q}-T$ diagram of this cooling process. It is apparent that a large $\Delta T$ exists in the first part of the evaporator. This ideally implies a small heat transfer area but also a high rate of exergy destruction.

\subsubsection{Cooling Concept 2}

Concept 2 utilizes two evaporative streams to cool the flow of hydrogen. The principle layout can be seen in Fig. 2a. Two hydrogen cooling heat exchangers are placed between the reduction valve outlet and the nozzle.

A $\dot{Q}-T$ diagram of this cooling process is shown in Fig. 2b. It is apparent that the load-share between the two heat exchangers is dependent on $T_{\text {evap }, H}$. Lowering $T_{\text {evap }, H}$ shifts the load from the low to the high-stage and vice versa. Introducing a second evaporation stage gives the possibility of decreasing the exergy destruction rate, compared to the one-stage concept, as the temperature gap between the hydrogen and the refrigerant can be reduced. This will then imply a larger heat transfer area, due to the reduced average temperature difference.

\subsubsection{Cooling Concept 3}

Concept 3 also utilizes two evaporative cold streams but has the high-stage situated upstream of the reduction valve, see Fig. 3a. The hydrogen is cooled prior to the forced adiabatic expansion in the reduction valve. The offset for the temperature increase induced by the Joule-Thomson effect is lowered in this case. The $\dot{Q}-T$ plot is shown in Fig. 3b. The temperature is first lowered from the hydrogen bank temperature, then throttled in the reduction valve, resulting in an adiabatic temperature increase and then cooled to the target temperature of $-40{ }^{\circ} \mathrm{C}$. This leads to a potential decrease in exergy destruction, at the expense of an increased heat transfer area. 


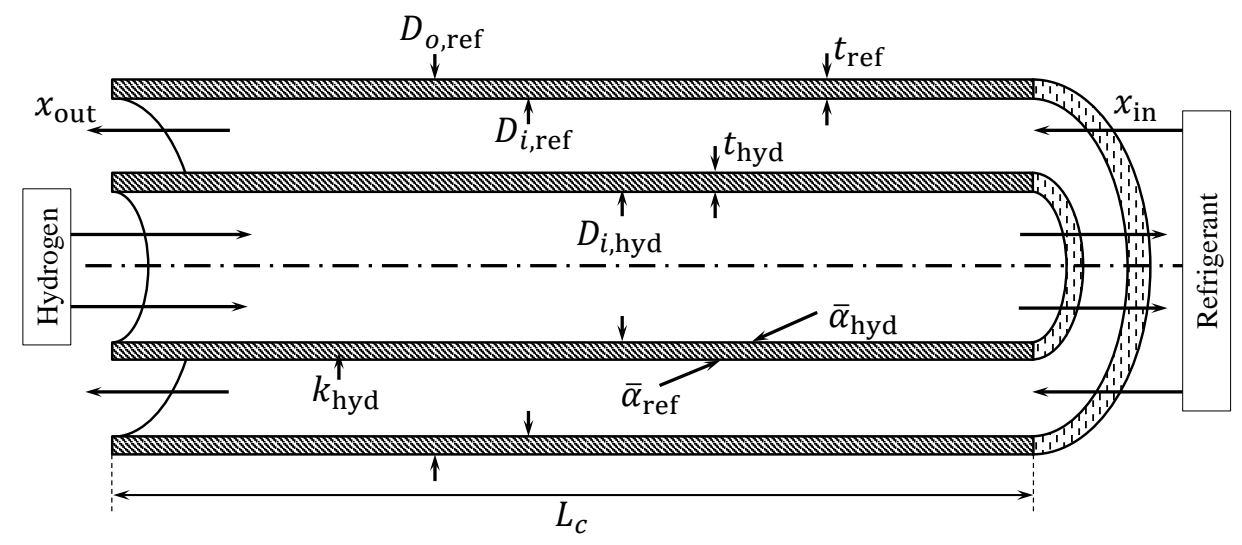

Figure 4: Principle sketch of one circuit of the coaxial tube evaporator.

The main advantage of Concept 3 compared to Concept 2 is that the high-stage evaporator does not have to be placed in the dispenser unit. This will allow part of the increased heat transfer area that is needed to reduce the exergy destruction to be placed in the hydrogen storage and process facility where the spatial constraints are not as rigorous.

\section{Method}

\subsection{Optimal intermediate hydrogen temperature}

For cooling Concepts 2 and 3 the thermally driven exergy destruction rate is linked to the intermediate temperature of the hydrogen $T_{\text {hyd,out, } H}$, see Figs. 2a and 3a. Assuming a constant pinch temperature difference of $5{ }^{\circ} \mathrm{C}$ on both the high and low-stage fixes the low-stage temperature to $T_{\text {evap, } L}=-45^{\circ} \mathrm{C}$ and the high-stage temperature to $T_{\text {evap }, H}=T_{\text {hyd }, \text { out }, H}=-5^{\circ} \mathrm{C}$.

It is of interest to evaluate how the thermally driven exergy destruction rate is related to the intermediate hydrogen temperature. As it is the objective of the two-stage concepts to reduce the exergy destruction caused by the finite temperature difference in the evaporator, the optimal choice of the intermediate hydrogen temperature was defined as the one that yields the highest reduction.

The thermally driven exergy destruction rate was calculated for each of the evaporator stages using Eq. (1)[13]. Here $T_{\text {hyd,avg }}$ and $T_{\text {ref,avg }}$ are the thermodynamic average temperatures for the hydrogen stream and refrigerant stream respectively. The definition of thermodynamic average temperature is given by Eq. (2)[13]. Constant pressure was assumed. Assuming there is no superheat in the refrigerant stream the thermodynamic average temperature is equal to the evaporation temperature.

$$
\begin{aligned}
& \dot{E}_{D}^{T}=T_{0} \dot{Q} \frac{T_{\text {hyd,avg }}-T_{\text {ref,avg }}}{T_{\text {hyd,avg }} T_{\text {ref,avg }}} \\
& T_{\text {avg }}=\frac{h_{\text {out }}-h_{\text {in }}}{s_{\text {out }}-s_{\text {in }}}
\end{aligned}
$$

Using Eqs. (1) and (2) together with energy and mass balance equations and an assumption of isenthalpic expansion in the reduction valve, a parameter variation study of $T_{\text {hyd,out, } H}$ was performed using the software Engineering Equation Solver (EES)[18].

\subsection{Numerical heat transfer model of coaxial tube evaporator}

\subsubsection{General assumptions}

A sketch of the principle of the evaporator design is given in Fig. 4. It is a counterflow heat exchanger with the hydrogen flow in the inner tube and the two-phase refrigerant flow in the annulus tube. The evaporator is flooded, hence the inlet condition is saturated liquid and only a partial evaporation is undertaken in the evaporator. The 


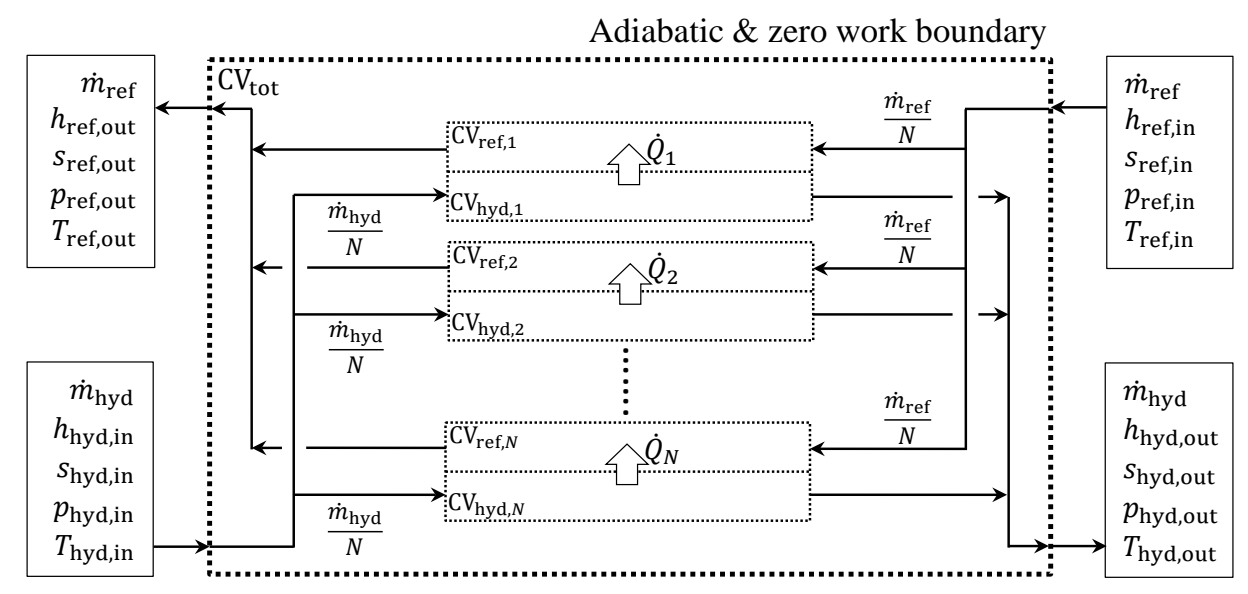

Figure 5: Control volume diagram for the heat transfer model of the coaxial tube evaporator

evaporator can be made up of a number of coaxial tubes in parallel connection, these will be referred to as circuits. The objective of the model is to determine the total length of tube required to construct the evaporator for different combinations of hydrogen and refrigerant pipe sizes as well as different numbers of circuits. The heat transfer model is developed in the software EES[18].

General assumptions:

- Steady state.

- No heat ingress from ambient.

- Constant heat flux on refrigerant side.

- Constant wall temperature on hydrogen side.

- Ideal distribution of hydrogen and refrigerant between evaporator circuits.

- Horizontal tubes.

- Inlet refrigerant vapour quality $x_{\mathrm{in}}=0$

- Outlet refrigerant vapour quality $x_{\text {out }}=0.25$

\subsubsection{Control volume definition and governing equation}

The model consists of a number of control volumes as may be seen in Fig. 5. The control volume $\mathrm{CV}_{\text {tot }}$ surrounds the entire evaporator and calculates the total heat load and overall heat transfer coefficient $U A$. $\mathrm{CV}_{\text {tot }}$ has an adiabatic and zero work boundary so it is assumed that there are no losses to the environment. The control volumes $\mathrm{CV}_{\text {ref, } 1 . . N}$ surrounds the refrigerant flow in each of the circuits. These calculate the average heat transfer coefficient and the pressure drop of the refrigerant. $\mathrm{CV}_{\text {hyd,1..N }}$ surrounds the hydrogen flow of each of the circuits and calculates the average heat transfer coefficient and the pressure drop of the hydrogen. Control volumes $\mathrm{CV}_{\text {ref, } 1 . . N}$ and $\mathrm{CV}_{\text {hyd,1..N }}$ exchange only heat, i.e. there is no exchange of work or mass. The heat exchange rate relation was derived by applying a first law energy balance to $\mathrm{CV}_{\text {tot }}$, Eq. (3). The required UA value was determined using Eq. (4) which was derived by combining Newton's law of convective cooling with the logarithmic mean temperature difference. The relationship between the required circuit length and the average heat transfer coefficient is given in Eq. (5).

$$
\begin{aligned}
& \dot{Q}=\dot{m}_{\text {hyd }}\left(h_{\text {hyd,in }}-h_{\text {hyd }, \text { out }}\right)=\dot{m}_{\text {ref }}\left(h_{\text {ref }, \text { out }}-h_{\text {ref }, \text { in }}\right) \\
& T_{\text {hyd,out }}=T_{\text {ref,in }}+\left(T_{\text {hyd,in }}-\bar{T}_{\text {ref }}\right) \exp \left(-\frac{\mathrm{UA}}{\dot{m}_{\text {hyd }} c_{p, \text { hyd }}}\right)
\end{aligned}
$$




$$
\mathrm{UA}=\left(\frac{1}{\bar{\alpha}_{\mathrm{hyd}} 2 \pi D_{i, \mathrm{hyd}} L_{c} N}+\frac{\ln \left(\frac{D_{o, \text { hyd }}}{D_{i, \mathrm{hyd}}}\right)}{k_{\mathrm{hyd}} 2 \pi L_{c} N}+\frac{1}{\bar{\alpha}_{\mathrm{ref}} 2 \pi D_{o, \text { hyd }} L_{c} N}\right)^{-1}
$$

\subsubsection{Heat transfer and pressure drop correlations}

Table 1: Heat transfer and pressure drop correlations by media and flow types.

\begin{tabular}{llll}
\hline Type & Media & Flow type & Correlation \\
\hline Heat transfer & Ammonia & two-phase & Shah[19] \\
coefficient & Hydrogen & laminar & Shah \& London[22] \\
& Hydrogen & turbulent & Chilton-Colburn[23], Churchill[24] \\
Pressure drop & Ammonia & two-phase & Muller-Steinhagen \& Heck[21], Ould[20] \\
& Hydrogen & laminar & Shah \& London[22] \\
& Hydrogen & turbulent & Zigrang and Sylvester[25] \\
\hline
\end{tabular}

Table 1 lists the correlations applied dependent on media and flow type. Shah's correlation[19] was used to predict the local heat transfer coefficient for the two-phase ammonia flow. The local heat transfer coefficient was evaluated for discrete values of vapour quality in the given range and then integrated to find the average. The hydraulic diameter of the annulus tubes was used to correct for the non-circular duct.

The pressure drop in the two-phase ammonia flow was calculated as the sum of the frictional and momentum pressure drop as described by Didi et al.[20]. Here the pressure gradient was calculated using the Müller-Steinhagen and Heck's correlation[21].

For laminar hydrogen flow, Reynold's number $<2300$ : the average heat transfer coefficient and pressure loss were calculated using correlations developed by Shah and London[22]. For turbulent flow, Reynold's number $>5000$ : the average heat transfer coefficient was calculated using the Chilton-Colburn analogy[23] with the Churchill friction factor[24]. The pressure drop was calculated using Zigrang and Sylvester[25]. Heat transfer coefficients and pressure drops in the laminar to turbulent transition range, Reynold's number between 2300-5000, were calculated by interpolating between the laminar and turbulent correlations. The heat transfer correlations applied to the hydrogen flow assume simultaneously developing hydrodynamic and thermal flow. The effect of developing flow is accounted for by multiplying by a factor related to the length to diameter ratio[26].

\subsubsection{Pipe sizes and material data}

Table 2: Inner and outer diameter and pipe wall thickness of refrigerant and hydrogen pipes.

\begin{tabular}{llllllll}
\hline \multicolumn{4}{c}{ Refrigerant } & & \multicolumn{4}{c}{ Hydrogen } \\
NPS & $D_{o}[\mathrm{~mm}]$ & $t[\mathrm{~mm}]$ & $D_{i}[\mathrm{~mm}]$ & NPS & $D_{o}[\mathrm{~mm}]$ & $t[\mathrm{~mm}]$ & $D_{i}[\mathrm{~mm}]$ \\
\hline DN32 & 42.16 & 1.651 & 38.858 & DN6 & 6.350 & 1.790 & 2.770 \\
DN40 & 48.26 & 1.651 & 44.958 & DN10 & 9.530 & 2.180 & 5.170 \\
DN50 & 60.33 & 1.651 & 57.028 & DN15 & 14.29 & 3.180 & 7.930 \\
DN65 & 73.03 & 2.108 & 68.814 & DN20 & 19.05 & 3.960 & 11.13 \\
DN80 & 88.90 & 2.108 & 84.684 & DN25 & 25.40 & 5.570 & 14.27 \\
\hline
\end{tabular}

Table 2 lists the dimensions of the hydrogen and refrigerant pipes that were examined. The refrigerant pipes are all nominal pipe size (NPS), schedule 5[27]. The hydrogen pipes are commercial medium pressure pipes approved for pressures up to $130 \mathrm{MPa}$. All pipes are manufactured in stainless steel 316, so the thermal conductivity is assumed to be the same, $k=0.016 \mathrm{~kW} / \mathrm{m}-\mathrm{k}$. Similarly, the absolute roughness was assumed to be the same for all pipes, $\epsilon=9 \cdot 10^{-5} \mathrm{~m}$. 


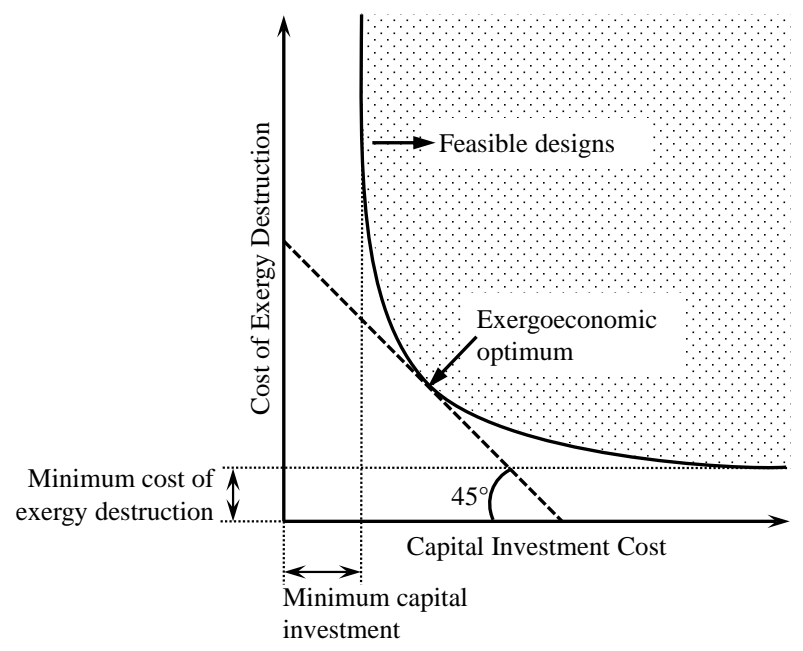

Figure 6: Graphical representation of the exergoeconomic optimum

\subsection{Exergy analysis}

To quantify the extent of irreversibilities in the evaporator in a measure comparable to the fuel of the system an exergy analysis is performed. As there is no mixing of chemical species or chemical reactions in the evaporator the exergy destruction is assumed to be purely physical. The physical exergy destruction can be split into two sources, the thermal part and the mechanical part. Here the thermal part is the exergy destruction caused by a finite temperature difference in the evaporator, while the mechanical part is the destruction caused by pressure loss.

The total exergy destruction rate, with contributions from both thermal and pressure driven sources, was calculated by imposing an exergy balance on $\mathrm{CV}_{\text {tot }}$ (adiabatic and zero-work boundary), as shown in Eq. (6)[13]. Here $e^{\mathrm{PH}}$ is the specific physical exergy, the definition of which is given by Eq. 7[13][28], where $h_{0}$ and $s_{0}$ are the specific enthalpy and entropy at the dead state in this case defined as $T_{0}=25^{\circ} \mathrm{C}$ and $p_{0}=1 \mathrm{~atm}$. For Concepts 2 and 3 the exergy balance is imposed on each stage individually.

$$
\begin{aligned}
& \dot{E}_{D}=\sum_{\text {in }} \dot{m}_{\text {in }} e_{\text {in }}-\sum_{\text {out }} \dot{m}_{\text {out }} e_{\text {out }}=\dot{m}_{\text {hyd }}\left(e_{\text {hyd }, \text { out }}^{\mathrm{PH}}-e_{\text {hyd,in }}^{\mathrm{PH}}\right)+\dot{m}_{\text {ref }}\left(e_{\text {ref,out }}^{\mathrm{PH}}-e_{\text {ref,in }}^{\mathrm{PH}}\right) \\
& e_{j}^{\mathrm{PH}}=h_{j}-h_{j, 0}-T_{0}\left(s_{j}-s_{j, 0}\right)
\end{aligned}
$$

To calculate the exergy destruction from thermal and pressure driven sources the physical exergy must be split into the thermal and mechanical parts. At a given thermodynamic state, defined by $T$ and $p$, the thermal part of the physical exergy can be calculated by an isobaric process to the dead state temperature $T_{0}$, while the mechanical part can be calculated by an isothermal process to the dead state pressure $p_{0}[29]$. The specific thermal and mechanical exergy is given by Eqs. (8) and (9)[30], here the subscript $M$ indicates the thermodynamic state of pressure $p$ and temperature $T_{0}$. It may be seen that by definition $e^{\mathrm{PH}}=e^{\mathrm{PH}, T}+e^{\mathrm{PH}, M}$.

$$
\begin{aligned}
& e_{j}^{\mathrm{PH}, T}=h_{j}-h_{j, M}-T_{0}\left(s_{j}-s_{j, M}\right) \\
& e_{j}^{\mathrm{PH}, M}=h_{j, M}-h_{j, 0}-T_{0}\left(s_{j, M}-s_{j, 0}\right)
\end{aligned}
$$

The thermal and pressure driven exergy destruction rates can be calculated by balancing the exergy flows as in Eq. (6).

\subsection{Exergoeconomic optimization and cost evaluation}

For component design the relation between the capital investment cost and the cost of exergy destruction can be described as may be seen in Fig. 6. By varying the geometry of the design a range of feasible solutions can be 
Table 3: Values for estimation of capital investment and operation costs

\begin{tabular}{lll}
\hline Material cost of stainless steel 316 & $c_{\text {mat }}$ & $5 \$ / \mathrm{kg}$ \\
Density of stainless steel 316 & $\rho_{\text {steel }}$ & $8025 \mathrm{~kg} / \mathrm{m}^{3}$ \\
Number of fuelling hours per year & $n_{\mathrm{oh}}$ & $223 \mathrm{~h} / \mathrm{year}$ \\
Unit cost of exergy fuel & $c_{f}$ & $67.5 \cdot 10^{-3} \$ / \mathrm{kWh}$ \\
Interest rate & $r$ & $5 \%$ \\
Life time & $I$ & 15 years \\
\hline
\end{tabular}

found (dotted area). The range of feasible solution is bounded by a pareto front, converging towards a minimum capital investment and a minimum cost of exergy destruction. Applied to a heat exchanger, such as the hydrogen cooling evaporator, this behaviour is explained as follows: by increasing the heat transfer area the investment cost is increased but the cost of exergy destruction is reduced. At an infinite area an thus infinite investment cost some exergy destruction will prevail thus leading to the minimum cost of exergy destruction. To reduce the heat transfer area will require either: an increased temperature difference or an increased pressure drop induced by increased flow velocity. Both will cause increased exergy destruction. No matter how much temperature difference and flow velocity are increased a certain area will still be needed to transfer the heat, thus leading to the minimum capital investment. The exergoeconomic optimum will be the solution found where the pareto front has a derivative of -1 , see Fig. 6 . The total cost of the component here is at a minimum. Moving left of the optimum, total cost will increase due to exergy destruction. Moving right of the optimum, total cost will increase due to capital investment.

The capital investment cost of the coaxial tube evaporator can be estimated based on the cost of the required material. The maintenance costs are neglected. The evaporator is constructed of two pipes both assumed to be of stainless steel 316. The specific cost per unit mass of this steel is listed in Table 3. The mass of steel required can be found using the pipe dimensions listed in Table 2, the total length calculated by the model and the steel density listed in Table 3[18]. The relation used to estimate the capital investment is given by Eq. (10).

$$
C^{\mathrm{CI}}=\frac{L \pi}{4}\left(\left(4 t_{\mathrm{hyd}}^{2}+4 t_{\mathrm{hyd}} D_{i, \mathrm{hyd}}\right)+\left(4 t_{\mathrm{ref}}^{2}+4 t_{\mathrm{ref}} D_{i, \mathrm{ref}}\right)\right) \rho_{\text {steel }} c_{\mathrm{mat}}
$$

To evaluate the cost of operating the coaxial tube evaporator the exergy fuel as well as the exergy destruction must be identified. The exergy destruction is found as described in section 2.3. For a vapour compression refrigeration system the fuel is the electricity supplied to the compressor. The unit cost of electricity is listed in Table 3[31]. To assess the evaporators operating cost in a term comparable to the investment cost the present value of the destroyed exergy fuel over the duration of the system lifetime has been calculated. This is given by Eq. (11)[13]. Here $n_{\mathrm{oh}}$ is the number of operating hours per year assuming 20 fuellings per day with a fuelling duration of $150 \mathrm{~s}, r$ is the interest rate, and $I$ is the system lifetime. The values for $n_{\mathrm{oh}}, r$ and $I$ may be found in Table 3 .

$$
C^{\mathrm{OP}}=\sum_{i=0}^{I} c_{f} \dot{E}_{D} n_{\mathrm{oh}} \frac{1}{(1+r)^{i}}
$$

The total cost introduced by the evaporator is the sum of the capital investment $C^{\mathrm{CI}}$ and the operational cost $C^{\mathrm{OP}}$ Eq. (12). This is therefore the objective function of the exergoeconomic optimization.

$$
C^{\mathrm{TI}}=C^{\mathrm{CI}}+C^{\mathrm{OP}}
$$

An indicator typically used in exergoeconomic analysis is the exergoeconomic factor[13]. This is given by Eq. (13). As may be seen this is the capital investment cost relative to the total cost and is thus a measure of the nonexergy related cost's impact on the total cost. The exergoeconomic factor is an indicator of how the total cost is best reduced. If $0<f<0.5$ : the main contribution to the total cost is the operational costs and thereby linked to the exergy destruction, the total cost is presumably best reduced by increasing the exergy efficiency of the component. If $0.5<f<1$ : the main contribution to the total cost is the capital investment. Therefore the investment should be reduced at the expense of a reduced exergy efficiency.

$$
f=\frac{C^{\mathrm{CI}}}{C^{\mathrm{CI}}+C^{\mathrm{OP}}}
$$




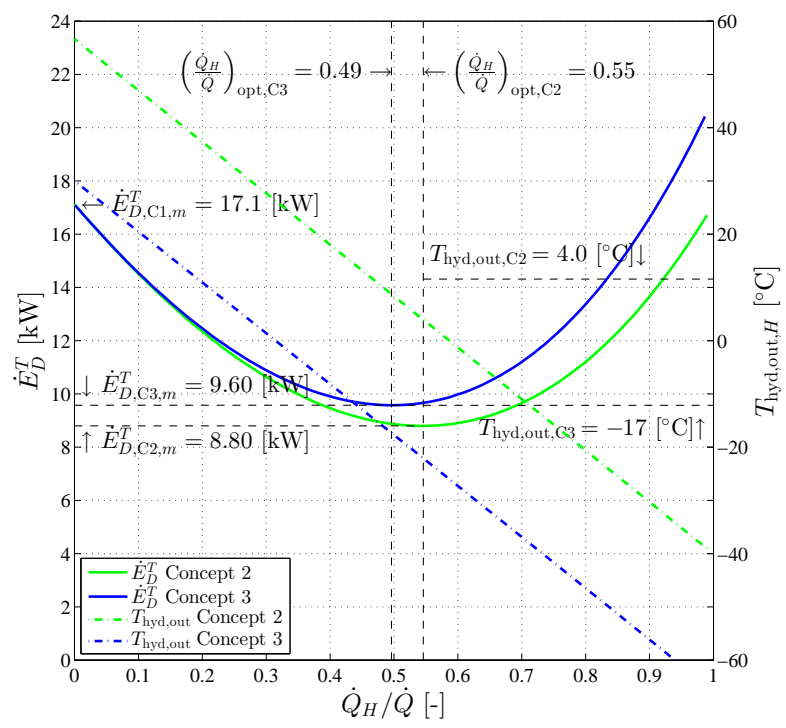

Figure 7: Thermal exergy destruction rate and intermediate hydrogen temperature as a function of the high-stage load-share for Concepts 2 and 3

\section{Results and discussion}

\subsection{Optimal intermediate hydrogen temperature}

Fig. 7 shows the variation in thermal exergy destruction and intermediate hydrogen temperature as a function of the load-share of the high-stage evaporator. The load-share is defined as $\mathrm{LS}=\dot{Q}_{H} / \dot{Q}$. Hence for $\mathrm{LS}=0$ the load is delivered only by the low-stage evaporator and Concepts 2 and 3 coincide with Concept 1 . For LS $=1$, all load is delivered by the high-stage evaporator, for Concept 2 this again coincides with Concept 1 . For Concept 3 to have the load on the high-stage evaporator only, forces the high-stage outlet temperature to be $-70{ }^{\circ} \mathrm{C}$ in order for the temperature out of the reduction valve to attain the target temperature of $-40{ }^{\circ} \mathrm{C}$.

As may be seen in Fig. 7, the exergy destruction rate is highly influenced by the choice of load-share and subsequently by the intermediate hydrogen temperature. It is seen that the exergy destruction rate decreases when increasing the load-share from $0 \rightarrow 0.55$ for Concept 2 and from $0 \rightarrow 0.49$ for Concept 3 . Increasing the load-share beyond these intervals causes the exergy destruction rate to increase again. Hence the optimal load-share for Concept 2 is $\mathrm{LS}_{\mathrm{opt}, \mathrm{C} 2}=0.55$ and $\mathrm{LS}_{\mathrm{opt}, \mathrm{C} 3}=0.49$ for Concept 3 . This corresponds to an intermediate hydrogen temperature of 4 ${ }^{\circ} \mathrm{C}$ for Concept 2 and $-17^{\circ} \mathrm{C}$ for Concept 3 .

At these intermediate hydrogen temperatures the thermal exergy destruction rate is reduced to $\dot{E}_{D, \mathrm{C} 2}^{T}=8.80 \mathrm{~kW}$ for Concept 2 and $\dot{E}_{D, \mathrm{C} 3}^{T}=9.60 \mathrm{~kW}$ for Concept 3 . The thermal exergy destruction rate for Concept 1 is $\dot{E}_{D, \mathrm{C} 1}^{T}=17.4$ $\mathrm{kW}$. Hence at the optimal point Concept 2 yields a reduction of the thermal exergy destruction rate of $49 \%$ compared with Concept 1. Concept 3 yields a reduction of $45 \%$.

\subsection{Optimal tube size combination and number of parallel circuits}

Using the optimal intermediate temperatures derived from the minimization of the thermal exergy destruction, the optimal combination of hydrogen and refrigerant pipe size has been found along with the optimal number of circuits. To evaluate this, the heat transfer model of the tube in tube evaporator was run for all combinations of the pipe sizes seen in Table 2. This was then combined with circuit numbers from 1 to 5 (1 to 10 for Concept 1).

Fig. 8 shows the total length $\left(L=L_{c} N\right)$ and exergy destruction rate for all feasible solutions for Concepts 1,2 and 3. It may be seen that the length of tube required varies greatly not only between the three concepts but also for the different combinations of tube sizes and circuit numbers. Further it may be seen that the exergy destruction converges against the minimum thermal destruction rates found in section 3.1 i.e. if a long enough tube length is accepted a 


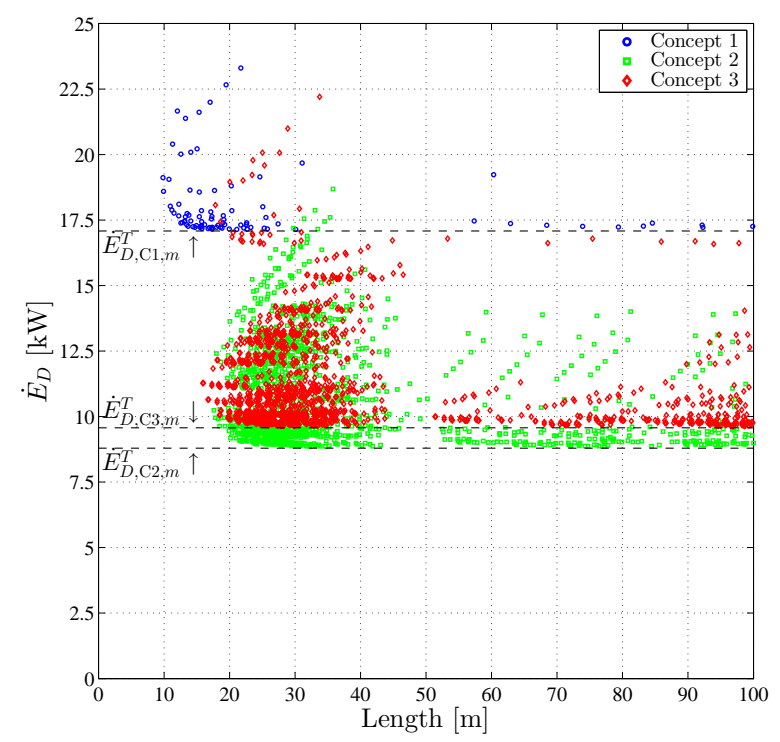

Figure 8: Exergy destruction rate and total tube length for all feasible solution of Concepts 1, 2 and 3

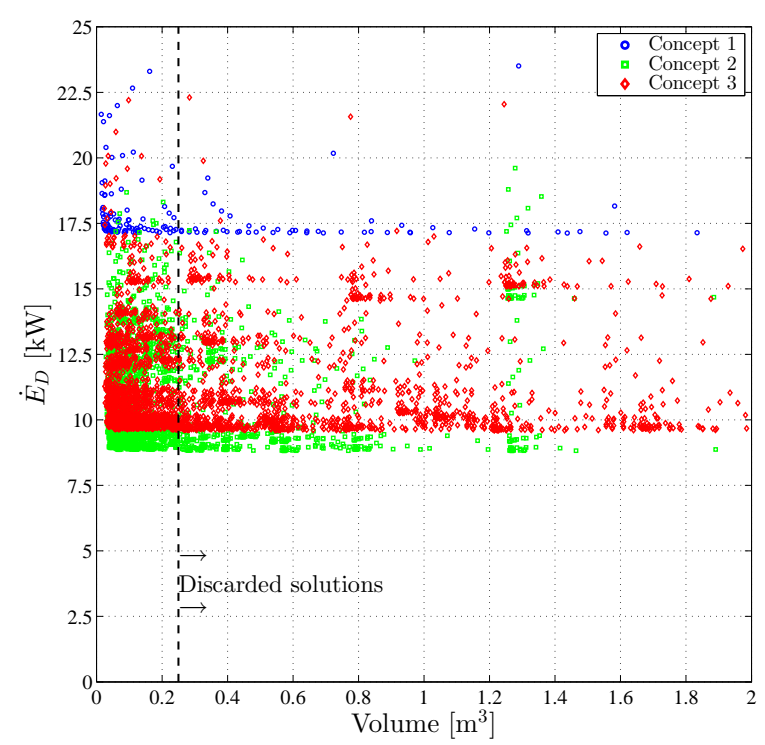

Figure 9: Exergy destruction rate and the volume occupied by the evaporator for all feasible solution of Concepts 1, 2 and 3

solution can be found that eliminates the pressure driven exergy destruction. On the other hand solutions with the same length can yield exergy destruction rates up to $50 \%$ larger than the minimized thermal destruction.

To comply with the spatial constraints in the dispenser it has been necessary to estimate the size occupied by the evaporator. The total volume taken up by the evaporator can be estimated by $V=\left(\frac{\pi}{4} D_{o \text {,ref }}^{2} L\right)$. Fig. 9 shows the volume of the evaporator and exergy destruction rate. As it may be seen the volume ranges from $0.01 \mathrm{~m}^{3}$ up to $2 \mathrm{~m}^{3}$, therefore some solutions may not fit into the dispenser. It has been chosen to discard all solutions with $V>0.25 \mathrm{~m}^{3}$.

Fig. 10 shows the capital investment cost and the operational cost for all three concepts. It may seen that the feasible solutions exhibit the trend proposed in Fig. 6. For Concept 1 it may be seen that the minimum capital investment is $C_{m}^{\mathrm{CI}}=140 \$$ while the minimum operational cost is $C_{m}^{\mathrm{OP}}=5575 \$$. For Concept 2 the minimal costs 


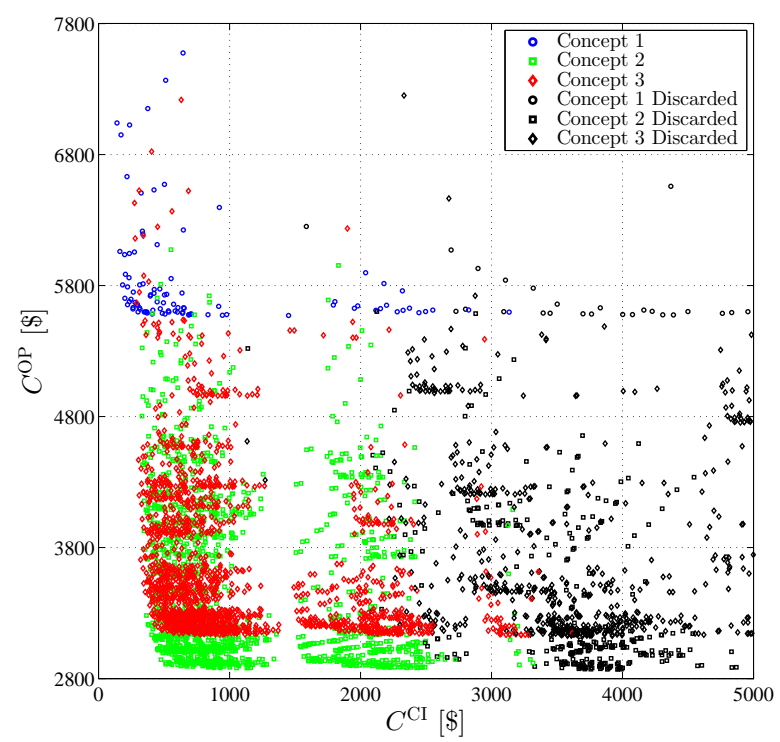

Figure 10: Capital investment cost and operational cost for all feasible solutions of Concepts 1,2 and 3

are $C_{m}^{\mathrm{CI}}=330 \$$ and $C_{m}^{\mathrm{OP}}=2880 \$$, while Concept 3 yields minimum costs of $C_{m}^{\mathrm{CI}}=305 \$$ and $C_{m}^{\mathrm{OP}}=3160 \$$.

Fig. 11 shows the solution for all three concepts closest to the point of minimum investment and minimum operational cost. For Concepts 2 and 3 this is shown for the high and low-stage individually. As there is not set any constraint on the combination of pipe sizes between the two stages it can be assumed that the optimum for the total evaporator is the sum of the optimum of the stages separately. It may be seen that the minimum total cost has been indicated on each of the evaporators on Figs. 11a-11e. Further it may be seen that iso-cost lines have been added to each of Figs. 11a-11e indicating the deviation in total cost for the near optimal solutions. From this it may be seen that many near optimal solutions exist. For Concept 1,15 combinations yield a total investment cost with less than a $2.5 \%$ increased total cost.

One exergoeconomic optimum has been found for each of the three concepts. The results are listed in Table 4. It may be seen that the optimum refrigerant pipe size for all concepts is DN40. The optimum hydrogen pipe for Concept 1 and the high-stage evaporator of Concept 2 is DN15. For the low-stage evaporator of Concept 2 and both stages of Concept 3: DN20 is the optimal hydrogen pipe size. Concept 2 yields the lowest total cost of $3422 \$$ which is $45 \%$ lower than the total cost of Concept 1 . Conversely, Concept 1 will occupy the least space with $28.7 \cdot 10^{-} 3 \mathrm{~m}^{3}, 39 \%$ lower than the most space consuming Concept 2. It should be noted that the main contribution to the total investment for all near optimal solutions is the operational cost. Although Concepts 2 and 3 almost halves the operational cost the capital investment cost still only accounts for $12-14 \%$ of the total cost. This is represented by the exergoeconomic factor $f$ also listed i Table 4. This implies that the evaporator would be improved best beyond this optimum by a further reduction of the exergy destruction.

It should be noted that these optima are based on the capital investment of evaporator material only. The increased cost of investing in a two-stage refrigeration system compared to a one-stage is not accounted for. Therefore these results alone cannot justify the viability of a two-stage system but the large reduction in total cost does suggest that a two-stage system could be preferable. To quantify this a complete exergoeconomic analysis of the refrigeration system should be performed. From the presented results alone it can be concluded that the increased capital investment in heat exchanger material is approximately one tenth of the savings in operational cost caused by the reduced exergy destruction. Of the two-stage concepts, Concept 2 is to be preferred over Concept 3.

A sensitivity analysis has been performed on the exergoconomic optimum solution for Concept 1 . It has been performed using the built in uncertainty propagation function in the EES software[18]. The assumptions for the exergoeconomic analysis and heat transfer model have been tested by calculating the total cost's sensitivity to these. Table 5 lists the results from the sensitivity analysis. As may be seen the total cost is most sensitive to change in the 

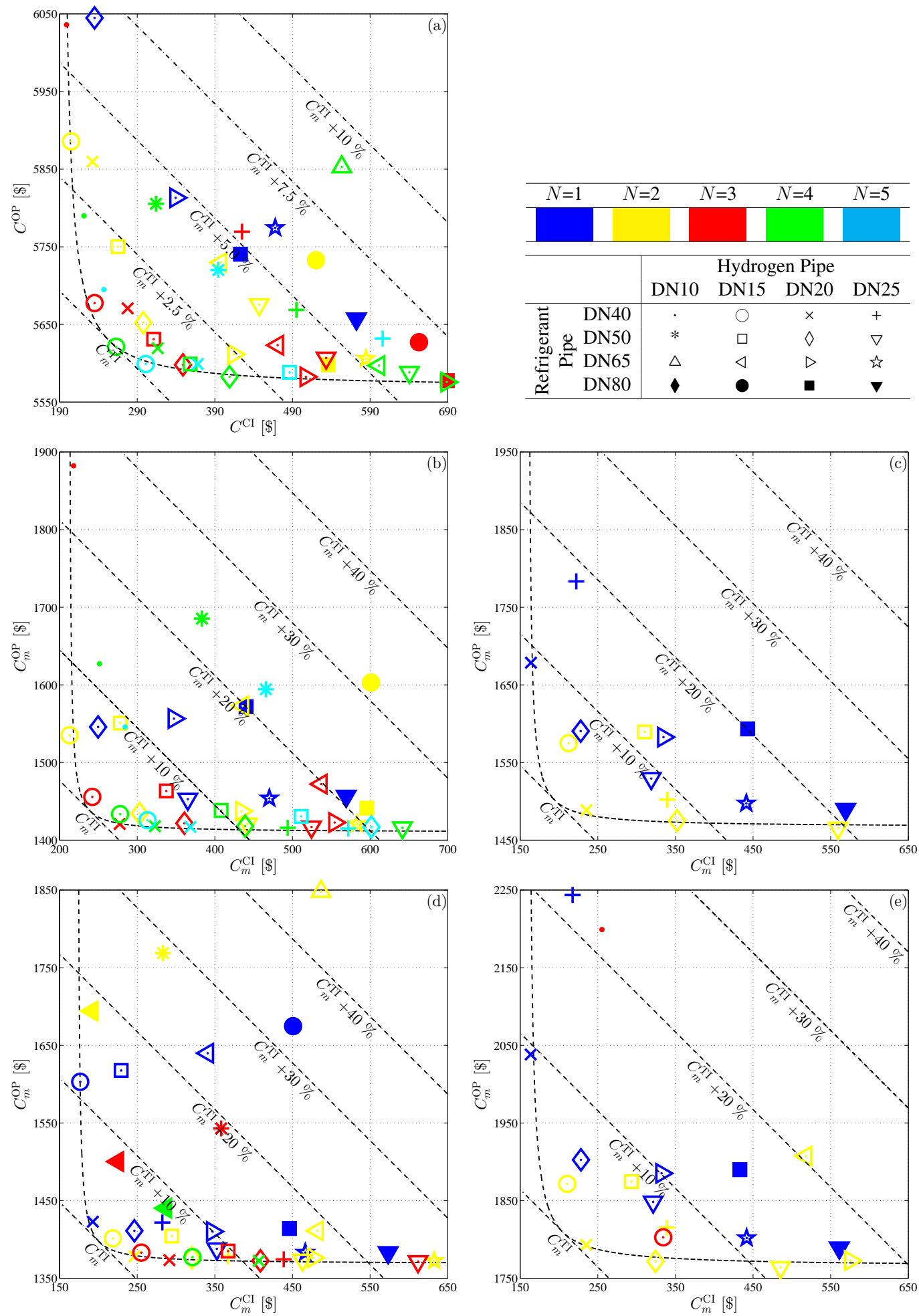

Figure 11: Exergoeconomic optimum and near optimum solutions for: (a) Concept 1. (b) Concept 2 high-stage. (c) Concept 2 low-stage. (d) Concept 3 high-stage. (e) Concept 3 low-stage. 
Table 4: Summary of the results from the exergoeconomic optimization

\begin{tabular}{ccccccccccccc}
\hline & $\begin{array}{c}C^{\mathrm{TI}} \\
{[\$]}\end{array}$ & $\begin{array}{c}C^{\mathrm{CI}} \\
{[\$]}\end{array}$ & $\begin{array}{c}C^{\mathrm{OP}} \\
{[\$]}\end{array}$ & $\begin{array}{c}f \\
{[-]}\end{array}$ & $\begin{array}{c}\dot{E}_{D} \\
{[\mathrm{~kW}]}\end{array}$ & $\begin{array}{c}\dot{E}_{D}^{T} \\
{[\mathrm{~kW}]}\end{array}$ & $\begin{array}{c}\dot{E}_{D}^{M} \\
{[\mathrm{~kW}]}\end{array}$ & HPS & RPS & $\begin{array}{c}L \\
{[-]}\end{array}$ & $\begin{array}{c}V \\
{[\mathrm{~m}]}\end{array}$ & $\begin{array}{c}V \\
{\left[\mathrm{~m}^{3}\right] \cdot 10^{-3}}\end{array}$ \\
\hline Concept 1 & 5884 & 262.8 & 5621 & 0.05 & 17.3 & 16.8 & 0.50 & $\mathrm{DN} 15$ & $\mathrm{DN} 40$ & 4 & 15.7 & 28.7 \\
\hline Concept 2 & 3422 & 477.3 & 2945 & 0.14 & 9.06 & 8.55 & 0.51 & - & - & - & 25.6 & 46.8 \\
High & 1698 & 242.1 & 1456 & 0.14 & 4.47 & 4.35 & 0.12 & DN15 & DN40 & 3 & 14.5 & 26.5 \\
Low & 1724 & 235.2 & 1489 & 0.14 & 4.59 & 4.20 & 0.39 & DN20 & DN40 & 2 & 11.1 & 20.3 \\
\hline Concept 3 & 3644 & 427.8 & 3216 & 0.12 & 9.90 & 9.06 & 0.84 & - & - & - & 20.2 & 37.0 \\
High & 1616 & 192.8 & 1423 & 0.12 & 4.38 & 4.03 & 0.35 & DN20 & DN40 & 1 & 9.10 & 16.7 \\
Low & 2028 & 235.0 & 1793 & 0.12 & 5.52 & 5.03 & 0.49 & DN20 & DN40 & 2 & 11.1 & 20.3 \\
\hline
\end{tabular}

Table 5: Sensitivity analysis, economic and heat transfer model assumptions influence on the total cost $C^{\mathrm{TI}}$

\begin{tabular}{clllll}
\hline Variable & & Value & \pm & Uncertainty & \%Uncertainty on $C^{\mathrm{TI}}$ \\
\hline Economic & & & & & \\
$c_{f}$ & {$[\$ / \mathrm{kWh}]$} & 0.0675 & \pm & 0.02 & $18.2 \%$ \\
$c_{m}$ & {$[\$ / \mathrm{kg}]$} & 5 & \pm & 4 & $0.24 \%$ \\
$n_{\text {oh }}$ & {$[$ hours $]$} & 223 & \pm 60 & $15.0 \%$ \\
$r$ & {$[\%]$} & 5 & \pm 4 & $19.0 \%$ \\
$I$ & {$[$ years $]$} & 15 & \pm 5 & $46.1 \%$ \\
Model & & & & & \\
$x_{\text {out }}$ & {$[-]$} & 0.25 & \pm 0.2 & $0.05 \%$ \\
$k$ & {$[\mathrm{~kW} / \mathrm{m}-\mathrm{K}]$} & 16 & \pm 2 & $0.00 \%$ \\
$\epsilon$ & {$[\mathrm{m}]$} & $9 \cdot 10^{-5}$ & $\pm 5 \cdot 10^{-6}$ & $0.00 \%$ \\
$\Delta T_{\text {pinch }}$ & {$\left[{ }^{\circ} \mathrm{C}\right]$} & 5 & \pm 4 & $1.4 \%$ \\
\hline
\end{tabular}

assumed lifetime of the system. Further, the uncertainty of the specific cost of exergy fuel, the number of operating hours and interest rate influence the total cost. While it is rather insensitive to the change in the specific material cost. The total cost is insensitive to the assumed values for the heat transfer model.

\section{Conclusion}

Three direct evaporation concepts for cooling hydrogen under fuelling in accordance with SAE-tir-J2601 and SAE-tir-J2600 is identified. This requires hydrogen to be supplied at $-40{ }^{\circ} \mathrm{C}$. At an ambient temperature of $30{ }^{\circ} \mathrm{C}$ this yields a peak cooling load of $72 \mathrm{~kW}$.

Based on a numerical heat transfer model and an exergoeconomic analysis the optimum combination of pipe size and circuit number is determined for the three identified concepts. Further a range of near optimal solutions is presented. For Concept 1 it is found that the minimum capital investment is $140 \$$ while the minimum operational cost is $5575 \$$. For Concept 2 this is $330 \$$ and $2880 \$$, while Concept 3 yields $305 \$$ and $3160 \$$. The optimum refrigerant pipe size is DN40 while the optimum hydrogen pipe is DN15 for Concept 1 and the high-stage of Concept 2 . For the low-stage of Concept 2 and both stages of Concept 3 the optimum hydrogen pipe size is DN20. Concept 2 yields the lowest total cost of 3422 \$ which is $45 \%$ lower than the total cost of Concept 1 and $7 \%$ lower than Concept 3. Conversely Concept 1 will occupy the least space with $28.7 \cdot 10^{-} 3 \mathrm{~m}^{3}, 39 \%$ lower than Concept 2 and $22 \%$ lower than Concept 3.

The results show that the two-stage concepts can reduce the total cost of the evaporator by up to $45 \%$ due to the reduced thermal exergy destruction. It is clear from this study that the capital investment in heat exchanger material is not of significant importance to the total cost. The evaporator is therefore best optimized by a reduction of exergy destruction. Concept 2 is the most profitable solution with a total cost $45 \%$ lower than Concept 1 and $7 \%$ lower than Concept 3 . 


\section{Bibliography}

[1] Rothuizen, E., Mérida, W., Rokni, M., Wistoft-Ibsen, M.. Optimization of hydrogen vehicle refueling via dynamic simulation. International Journal of Hydrogen Energy 2013;38(11):4221-4231. doi:10.1016/j.ijhydene.2013.01.161.

[2] Rothuizen, E., Rokni, M.. Optimization of the overall energy consumption in cascade fueling stations for hydrogen vehicles. International Journal of Hydrogen Energy 2014;39(1):582-592. doi:10.1016/j.ijhydene.2013.10.066.

[3] Liu, Y.L., Zhao, Y.Z., Zhao, L., Li, X., gang Chen, H., Zhang, L.F., et al. Experimental studies on temperature rise within a hydrogen cylinder during refueling. International Journal of Hydrogen Energy 2010;35(7):2627 - 2632. doi:10.1016/j.ijhydene.2009.04.042.

[4] Zhao, L., Liu, Y., Yang, J., Zhao, Y., Zheng, J., Bie, H., et al. Numerical simulation of temperature rise within hydrogen vehicle cylinder during refueling. International Journal of Hydrogen Energy 2010;35(15):8092 - 8100. doi:10.1016/j.ijhydene.2010.01.027.

[5] Galassi, C., Baraldi, D., Iborra, B., Moretto, P.. Cfd analysis of fast filling scenarios for 70 mpa hydrogen type iv tanks. International Journal of Hydrogen Energy 2012;37(8):6886 - 6892. doi:10.1016/j.ijhydene.2012.01.041.

[6] SAE-International, . Compressed hydrogen vehicle fueling connection devices - technical information report j2600. Tech. Rep.; SAE International; 2008.

[7] SAE-International, . Fueling protocol for light duty gaseous hydrogen surface vehicles - technical information report j2601. Tech. Rep.; SAE International; 2010

[8] Morosuk, T., Tsatsaronis, G.. Advanced Exergetic Evaluation of Refrigeration Machines Using Different Working Fluids. Energy 2009;34(12):2248-2258. doi:10.1016/j.energy.2009.01.006.

[9] Dicken, C., Mérida, W.. Measured effects of filling time and initial mass on the temperature distribution within a hydrogen cylinder during refuelling. Journal of Power Sources 2007;165(1):324 - 336. doi:10.1016/j.jpowsour.2006.11.077.

[10] Rothuizen, E., Abel, M., Rokni, M., Elmegaard, B.. Using a Potassium Acetate Solution for Cooling High Pressure Hydrogen in a Prototype Heat Exchanger. 2011, p. ID 536.

[11] Tsatsaronis, G.. Thermoeconomic analysis and optimization of energy systems. Progress in Energy and Combustion Science 1993;19(3):227 - 257. doi:http://dx.doi.org/10.1016/0360-1285(93)90016-8.

[12] Kotas, T.. The exergy method of thermal plant analysis. Butterworths; 1985. ISBN 9780408013505.

[13] Bejan, A., Tsatsaronis, G., Moran, M.. Thermal Design and Optimization. Wiley-Interscience publication; Wiley; $1996 . \quad$ ISBN 9780471584674.

[14] Eryener, D.. Thermoeconomic optimization of baffle spacing for shell and tube heat exchangers. Energy Conversion and Management 2006;47(11-12):1478 - 1489. doi:http://dx.doi.org/10.1016/j.enconman.2005.08.001.

[15] Can, A., Buyruk, E., Eryener, D.. Exergoeconomic analysis of condenser type heat exchangers. Exergy, An International Journal 2002;2(2):113 - 118. doi:http://dx.doi.org/10.1016/S1164-0235(01)00051-6.

[16] Zubair, S.M.. Thermoeconomic considerations in the design and rating of two-phase heat exchangers. Energy 1998;23(12):1057 - 1063. doi:http://dx.doi.org/10.1016/S0360-5442(98)00061-9.

[17] Granryd, E.. Refrigerating Engineering. Royal Institute of Technology, KTH, Department of Energy Technology, Division of Applied Thermodynamics and Refrigeration; 2009. ISBN 9789174154153

[18] Klein, S.. Engineering equation solver academic professional v9.170. 2012.

[19] Shah, M.. Chart correlation for saturated boiling heat transfer: equations and further study. ASHRAE Transactions 1982;88, part 1.:185-196.

[20] Ould Didi, M., Kattan, N., Thome, J.. Prediction of two-phase pressure gradients of refrigerants in horizontal tubes. International Journal of Refrigeration 2002; Vol 25:935-947.

[21] Müller-Steinhagen, H., Heck, K.. A simple friction pressure drop correlation for two-phase flow in pipes. Chemical Engineering and Processing: Process Intensification 1986;20(6):297 - 308. doi:10.1016/0255-2701(86)80008-3.

[22] Shah, R., London, A.. Laminar flow forced convection in ducts. Academic Press 1978;.

[23] Chilton, T., Colburn, A.. Mass transfer (absorption) coefficients prediction from data on heat transfer and fluid friction. Industrial \& Engineering Chemistry 1934;26(11):1183-1187. doi:10.1021/ie50299a012.

[24] Churchill, S.. Friction-factor equation spans all fluid-flow regimes. Chemical Engineering 1977;84(24):91-92.

[25] Zigrang, D., Sylvester, N.. Explicit approximations to the solution of colebrook's friction factor equation. AIChE Journal 1982;Vol 28:514-515.

[26] Nellis, G., Klein, S.. Heat Transfer. Cambridge University Press; 2009. ISBN 9781139476614.

[27] of Mechanical Engineers, A.S.. Welded and seamless wrought steel pipes. ASME B3610M-2004 2004;

[28] Bejan, A.. Advanced engineering thermodynamics. 3 ed.; New York: Wiley; 2006. ISBN 04716776399780471677635.

[29] Tsatsaronis, G.. Definitions and nomenclature in exergy analysis and exergoeconomics. Energy 2007;32(4):249-253. doi:10.1016/j.energy.2006.07.002.

[30] Morosuk, T., Tsatsaronis, G.. A new approach to the exergy analysis of absorption refrigeration machines. Energy 2008;33(6):890-907. doi:10.1016/j.energy.2007.09.012.

[31] Tsatsaronis, G., Park, M.. On avoidable and unavoidable exergy destructions and investment costs in thermal systems. Energy Conversion and Management 2002;43(9-12):1259-1270. doi:10.1016/S0196-8904(02)00012-2. 